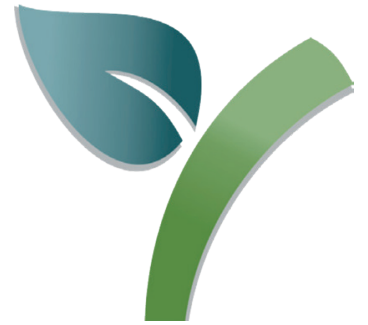

LIMA BEAN: VIRAL AND FUNGAL DISEASES

\section{FEIJÃO-FAVA: DOENÇAS VIRAIS E FÚNGICAS}

\author{
José Evando Aguiar Beserra Jr ${ }^{1 *}$, Beatriz Meireles Barguil ${ }^{2}$
}

\section{RESUMO}

O feijão-fava (Phaseolus lunatus L.) é cultivado majoritariamente por pequenos produtores da região Nordeste do Brasil. Apesar da importância econômica e social, os estudos sobre etiologia, epidemiologia e manejo de doenças foi por muito tempo negligenciada. Esta revisão traz as informações mais recentes sobre as principais doenças do feijão-fava no Brasil, que tem como agentes etiológicos os vírus e os fungos. São abordados aspectos da sintomatologia, etiologia e manejo do mosaico e mosaico dourado, antracnose, podridão de carvão, murcha de fusário e podridão do colo.

PALAVRAS-CHAVE: Antracnose, Podridão de carvão, Phaseolus lunatus, Manejo de doenças, Viroses.

\section{ABSTRACT}

Lima bean (Phaseolus lunatus L.) is mostly cultivated by small producers in the Northeast region of Brazil. Despite the economic and social importance, studies on etiology, epidemiology and disease management have long been neglected. This review brings the most recent information about the main Lima bean diseases in Brazil, which have viruses and fungi as etiological agents. Aspects of the symptomatology, etiology and management of mosaic and golden mosaic, anthracnose, charcoal rot, fusarium wilt and colon rot are addressed.

KEYWORDS: Anthracnose, Charcoal rot, Phaseolus lunatus, Disease management, Viruses.

\section{INTRODUÇÃO}

Dentre os feijões cultivados para o consumo humano, o feijão-fava (Phaseolus lunatus L.) é representativo nos cenários agrícola, econômico e cultural para a população da região Nordeste do Brasil, uma vez que é apresentado como alternativa da sustentabilidade da produção de alimentos (CHEL-GUERRERO et al. 2012; MOSES et al. 2012).

O feijão-fava apresenta elevado potencial de cultivo, diversidade genética e adaptação a diferentes condições climáticas (VIEIRA 1992; LONG et al. 2014; GOMES et al. 2020). No Brasil, destaca-se como espécie de subsistência, sendo produzida em regime de sequeiro, principalmente por produtores do setor da agricultura familiar (SANTOS et al. 2002).

A região Nordeste é responsável por 99,4\% da produção de feijão-fava do país, tendo alcançado rendimento médio de $352 \mathrm{~kg} / \mathrm{ha}$ (IBGE 2020), valor muito inferior ao potencial da cultura (LONG et al. 2014). Em 2019, os principais produtores foram os Estados do Ceará, Paraíba, Rio Grande do Norte e Piauí (IBGE 2020). Nessa região, há elevada instabilidade produtiva, o que contribui para a significativa flutuação da produção dessa leguminosa. O baixo rendimento e a grande oscilação nas produções de-

${ }^{1}$ Universidade Federal do Piauí (UFPI), Centro de Ciências Agrárias, Departamento de Fitotecnia, 64049-550, Teresina, PI, Brasil. ${ }^{2}$ Universidade Estadual do Piauí (UESPI), Curso de Ciências Biológicas, Centro de Ciências da Natureza, 64002-150, Teresina, PI, Brasil. *Autor para correspondência: evando@ufpi.edu.br 
vem-se ao fato de ser uma cultura que tem recebido pouca atenção por parte de órgãos de pesquisa e extensão. Além disso, os sistemas produtivos são caracterizados pelo pouco uso de tecnologias (GOMES et al. 2015).

A carência de registros de doenças e identificação dos agentes etiológicos, têm incrementado a vulnerabilidade da cultura, elevando o risco de perdas econômicas por causa de problemas fitossanitários e a dificuldade para o manejo adequado. No entanto, na última década, estudos sobre diferentes aspectos da cultura do feijão-fava, dentre eles a identificação dos agentes etiológicos de doenças, principalmente de etiologia viral e fúngica foram conduzidos. A seguir serão apresentadas as principais doenças de etiologia viral e fúngica, que são fatores de risco na quantidade e na qualidade de grãos de feijão-fava no território brasileiro.

\section{DOENÇAS CAUSADAS POR VÍRUS}

As informações sobre a ocorrência de espécies de vírus capazes de infectar naturalmente o feijão-fava são escassas. De acordo com Costa (1995) duas viroses ocorrem nessa cultura: o mosaico dourado e o mosaico. Apesar dessas doenças serem de ocorrência comum, seus agentes etiológicos foram por muito tempo desconhecidos. Esse panorama vem passando por mudanças, pois diversos agentes etiológicos de doenças do feijão-fava vêm sendo descritos.

\section{MOSAICO DOURADO}

O mosaico dourado é uma doença de ocorrência comum nos campos de cultivo de feijão-fava na região Nordeste do Brasil (SILVA et al. 2015). Entretanto, não há informações sobre as perdas provocadas por essa doença. Duas espécies de vírus foram relatadas em associação com plantas de feijão-fava, além de plantas não cultivadas, com sintomas de mosaico dourado nessa região: bean golden mosaic virus (BGMV) e macroptilium yellow spot virus (MaYSV), ambos pertencentes ao gênero Begomovirus, família Geminiviridae (RAMOS-SOBRINHO et al. 2014).

O BGMV é um importante patógeno do feijoeiro (Phaseolus vulgaris L.) desde a década de 1970 (FARIA \& MAXWELL 1999), capaz de causar até $100 \%$ de perdas na produção de feijão-comum (MORALES 2006). O vírus predomina em plantações de feijão-fava no Brasil, e feijão-comum afetadas pelo mosaico dourado no Brasil (RAMOS-SOBRINHO et al. 2014) e na Argentina (FARIA \& MAXWELL 1999), o que indica que o patógeno está bem adaptado a estas hospedeiras. As infecções pelo BGMV ocorrem principalmente por inóculo primário transmitido pela mosca-branca, que podem ter as plantas espontâneas como fonte de inóculo, enquanto a transmissão secundária planta a planta pelo vetor influencia a epidemia, devido à distribuição agregada do vetor nas plantações (SILVA et al. 2015).

O MaYSV foi descrito infectando plantas de feijão-de-rola (Macroptilium lathyroides L.), calopogônio (Calopogonium mucunoides Desv.) canavália (Canavalia sp.) e rapadura-de-cavalo (Desmodium glabrum (Mill.)), todas da família Fabaceae, na região Nordeste (SILVA et al. 2012; FONTENELE et al. 2016). Os sintomas de mosaico amarelo, enrolamento foliar e enfezamento são frequentemente observados em plantas de feijão-fava infectadas com BGMV e MaYSV (Fig. 1).

MaYSV é a espécie de begomovirus prevalente em feijão-fava no estado de Alagoas, e a sua população apresenta maior variabilidade genética, em comparação com a população de BGMV. Os eventos de recombinação intraespecífica encontrados na população de MaYSV explicam, ao menos parcialmente, a elevada variabilidade genética descrita (RAMOS-SOBRINHO et al. 2014). MaYSV apresenta relacionamento filogenético próximo com blainvillea yellow spot virus (BIYSV), vírus encontrado apenas no Brasil (CASTILLO-URQUIZA et al. 2008).

Ambos os vírus são provavelmente transmitidos pela mosca-branca Bemisia tabaci Gennadius (Hemiptera: Aleyrodidae) Middle East-Asia Minor 1 (MEAM1, anteriormente denominada biotipo B), o tipo mais disseminado no país (MORAES et al. 2018). Embora B. tabaci tenha sido identificada como vetor do BGMV (COSTA 1965), ainda não se conhece o biotipo que transmite o MaYSV em feijão-fava.

\section{MOSAICO}

O mosaico do feijão-fava tem como agentes causais conhecidos o cowpea aphid-borne mosaic virus (CABMV, gênero Potyvirus, família Potyviridae), cucumber mosaic virus (CMV, gênero Cucumovirus, família Bromoviridae), cowpea mild mottle virus (CPMMV, gênero Carlavirus, família Betaflexiviridae) e cowpea severe mosaic virus (CPSMV, gênero Comovirus, família Secoviridae). Os quatro vírus fo- 

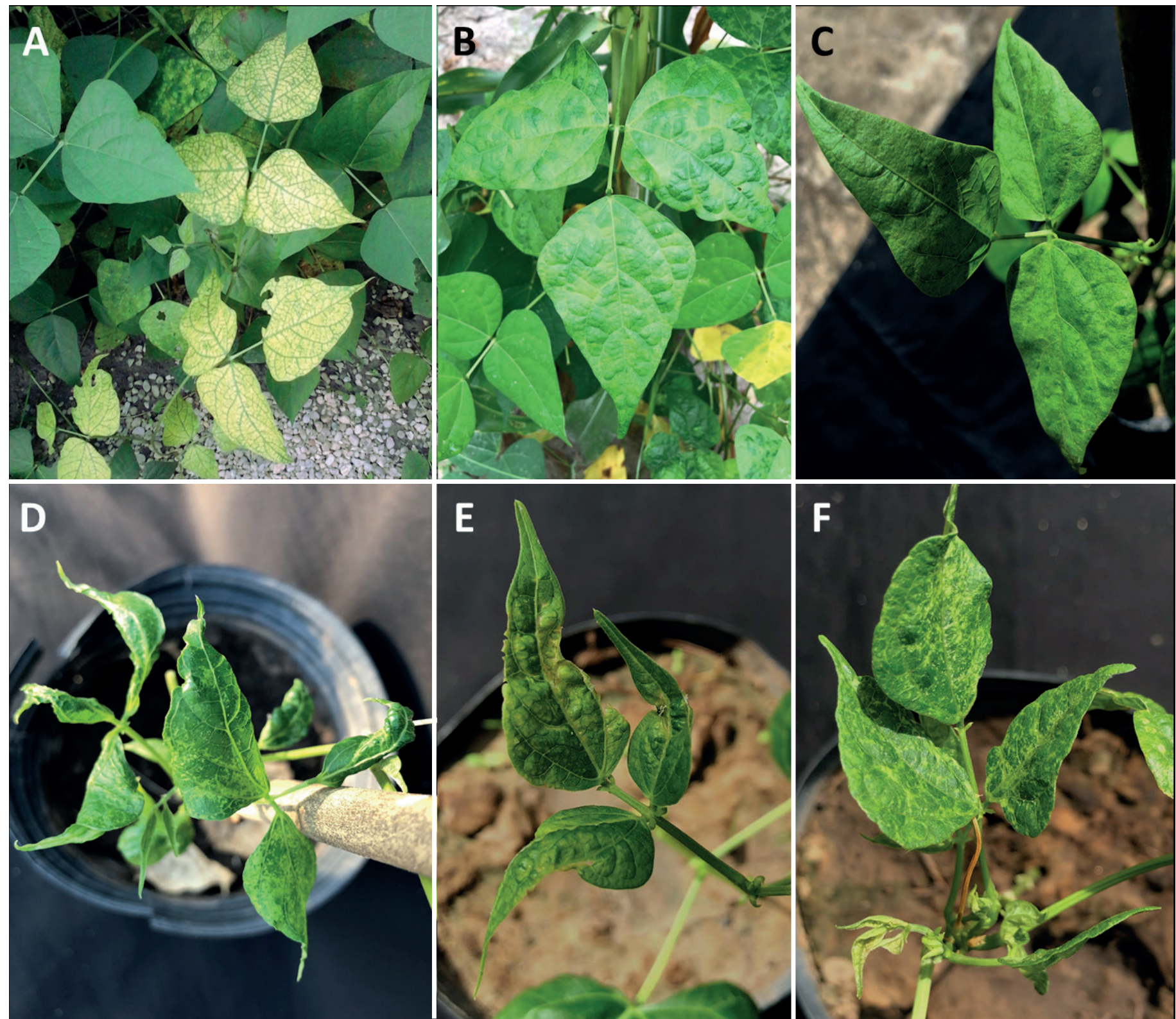

Figura 1. Sintomas em feijão-fava. Mosaico dourado (A) e mosaico (B) em campo. Plantas (var. Branquinha) inoculadas com extrato vegetal infectado com CPMMV (C), CABMV (D), CMV (E) e CPSMV (F). Fonte: autores.

ram identificados em plantas de feijão-fava exibindo sintomas de mosaico, deformação do limbo foliar e, em menor frequência, bolhosidades (MEDEIROS et al. 2020). Desses quatro vírus, apenas o CABMV já havia sido identificado causando doença em feijão-fava. O vírus foi primeiramente identificado por ELISA indireto com antisoro policlonal, no estado de Pernambuco (ANDRADE et al. 2001). Os demais vírus (CMV, CPMMV e CPSMV) apenas tiveram sua ocorrência registrada recentemente nos estados do Ceará e Piauí (MEDEIROS et al. 2020). Além disso, o feijão-fava também pode ser infectado experimentalmente pelo southern bean mosaic virus (SBMV, gênero Sobemovirus, família Solemoviridae), um vírus já detectado no Brasil em feijão-comum e em soja (GASPARIN et al. 2005).

\section{COWPEA APHID-BORNE MOSAIC VIRUS (CAB- MV)}

O CABMV é o agente causal do mosaico do feijão-caupi (Vigna unguiculata (L.) Walp) (BOCK $\&$ CONTI 1974). Esse vírus apresenta ampla distribuição geográfica no Brasil, onde infecta leguminosas como o feijão-caupi, feijão-da-praia ( $C a$ navalia rosea (Sw.) DC.) (KITAJIMA et al. 2008), amendoim (Arachis hypogaea L.) (PIO-RIBEIRO et al. 2000), feijão-fava (MEDEIROS et al. 2020), e uma espécie não leguminosa, o maracujazeiro (Passiflora edulis f. flavicarpa) (NASCIMENTO et al. 2006).

Os sintomas mais comuns induzidos pelo CABMV em plantas de feijão-fava variedades Branquinha e Boca de Moça são mosaico, defor- 
mação do limbo foliar, bolhosidade e redução do crescimento da planta (Fig. 1). Os sintomas são visíveis a partir do oitavo dia após a inoculação (MEDEIROS et al. 2020). Os mesmos sintomas frequentemente são observados em cultivares de feijão-caupi inoculadas mecanicamente com o CABMV (OLIVEIRA et al. 2012). O CABMV parece ser de ocorrência comum em plantações de feijão-fava, uma vez que $47,2 \%$ de plantas sintomáticas que foram coletadas em municípios dos Estados do Ceará e Piauí estavam infectadas com o vírus, além de frequentes infecções mistas com CMV e CPMMV (MEDEIROS et al. 2020).

É sabido que as condições que induzem grandes populações de afídeos vetores como Aphis spp. e Myzus persicae é a presença de espécies de plantas (hospedeiros naturais), que desempenham papel fundamental nas epidemias do endurecimento dos frutos do maracujazeiro causadas pelo CABMV (GARCÊZ et al. 2015). Em feijão-fava são escassos os estudos de transmissão de vírus por afídeos, muito embora seja frequente a ocorrência de Aphis craccivora colonizando plantas em campo (FORTES PORTELA et al. 2019). Não existem estudos sobre a transmissão do CABMV por sementes de feijão-fava.

A caracterização biológica de isolados de CABMV de maracujazeiro, e de outros hospedeiros, tem indicado que estes são capazes de infectar feijão-caupi e feijão-comum, mas diferem na capacidade de infectar o maracujazeiro (NASCIMENTO et al. 2006). Esses isolados podem ser divididos em dois grupos baseado na severidade de sintomas que causam em feijão-caupi e feijão-comum. Contudo, análises filogenéticas baseadas nas sequências de aminoácidos da proteína da capa proteica, incluindo sequência de isolados de CABMV de outros países, têm revelado que os agrupamentos são formados com base na origem geográfica do isolado (NASCIMENTO et al. 2006). Além disso, a comparação de genomas completos de dois isolados brasileiros de CABMV, no qual MG-Avr, isolado de maracujazeiro (e que infecta feijão-caupi) e BR1, isolado de amendoim (e que infecta feijão-caupi, mas não maracujazeiro) revelou elevada identidade de sequência nucleotídica, inclusive com um isolado africano (BARROS et al. 2011). Elevada variação foi encontrada na extremidade 5' entre os isolados brasileiros e o africano. Contudo, essa variação não foi relacionada com as proprie- dades biológicas dos isolados. Não foi observada correlação geográfica, nem por hospedeiro, na análise filogenética dos isolados obtidos de feijãofava, com os demais isolados brasileiros de CABMV (MEDEIROS et al. 2020).

\section{CUCUMBER MOSAIC VIRUS (CMV)}

O CMV é um dos vírus de plantas mais comuns, capaz de infectar mais de 1200 espécies, dentre elas muitas leguminosas cultivadas (ZITTER \& MURPHY 2009). Embora comumente não cause sintoma severo nas plantas que infetam, o CMV é capaz de interagir sinergicamente com outros vírus de importância econômica como aqueles do gênero Potyvirus, o que resulta em aumento na severidade da doença (WANG et al. 2002). Em feijão-fava, o CMV induz sintomas leves de mosaico em folhas jovens a partir dos 20 dias após a inoculação (d.a.i.), e aos 40 d.a.i. o mosaico torna-se mais severo. Não foram observados outros sintomas em feijão-fava, variedades Branquinha e Boca de Moça, quando inoculadas com um isolado de CMV (MEDEIROS et al. 2020).

De acordo com o relacionamento sorológico e identidade do ácido nucleico, isolados de CMV foram classificados em dois subgrupos principais denominados subgrupo I e subgrupo II (PALUKAITIS \& GARCIA-ARENAL 2003). Considerando as comparações de sequências nucleotídicas da ORF $3 b$ do RNA 3 , incluindo a região de codificação da proteína do capsídeo, e análise filogenética, os isolados de CMV de feijão-fava pertencem ao subgrupo IA (MEDEIROS et al. 2020). Esses resultados reforçam aqueles de Eiras et al. (2004), de que no Brasil há prevalência do CMV subgrupo I.

Não existem estudos sobre a transmissão do CMV por vetores, tampouco por sementes de feijão-fava.

\section{COWPEA SEVERE MOSAIC VIRUS (CPSMV)}

O CPSMV, agente causal do mosaico severo do feijão-caupi, é considerado fator limitante na produção dessa cultura no Brasil, pois dependendo da cultivar e da época de inoculação, o CPSMV pode reduzir a produção em até $85 \%$ (BOOKER et al. 2005). A planta infectada apresenta sintomas de mosaico, bolhosidade e nanismo. Em soja, o CPSMV reduz o tamanho, o peso médio dos grãos, o rendimento e taxa de germinação de sementes (ANJOS \& LIN 1984). 
Em feijão-fava, variedades Branquinha e Boca de Moça, o CPSMV induziu: lesões cloróticas aos 4 d.a.i.; sintomas de mosaico, bolhosidade e deformação do limbo nas folhas não inoculadas aos 7 d.a.i.; necrose na extremidade superior do caule e pontos necróticos em folhas jovens aos 11 d.a.i.; morte de brotos terminais, pontos necróticos e queda prematura das folhas aos 17 d.a.i.; nanismo aos 35 d.a.i. (MEDEIROS et al. 2020). Sintomas semelhantes foram relatados por Lin et al. (1981), Coelho et al. (1992) e Oliveira et al. (2012) em feijão-caupi inoculados mecanicamente com o CPSMV.

A transmissão do CPSMV ocorre por insetos da família Chrysomelidae, conhecidos popularmente como vaquinhas. As espécies Cerotoma arcuata e Diabrotica speciosa estão relacionadas com a transmissão em feijão-caupi (COSTA et al. 1978). O vírus não é transmitido por sementes de feijão-caupi (LIMA et al. 1989). Em feijão-fava, não são conhecidos os vetores associados à transmissão do CPSMV, e não há informações sobre a transmissão do vírus por sementes.

A primeira menção de um comovírus infectando naturalmente feijão-fava foi feita por Costa et al. (1991). Na ocasião, um comovírus foi identificado em uma planta originada a partir de semente infectada na região de Jataí, Goiás. No entanto, pelas técnicas utilizadas na época, não foi possível identificar a espécie de comovírus. Em 2020, em levantamento de vírus em plantas de feijão-fava em estados do nordeste brasileiro, foi encontrada uma planta infectada em 55 plantas sintomáticas analisadas, isto é, incidência de 1,81\% (MEDEIROS et al. 2020). A baixa incidência deve-se, provavelmente, ao fato do feijão-fava não ser hospedeiro preferencial dos insetos vetores. Essa hipótese é baseada na ausência de vaquinhas (insetos vetores do CPSMV) observadas nas plantações de feijão-fava analisadas (Professor José Evando Aguiar Beserra Jr.: informação pessoal).

Desde o primeiro relato da incidência do CPSMV no Brasil, diversos trabalhos têm indicado certo grau de variabilidade entre os isolados desse vírus. Entretanto, a variabilidade conhecida do CPSMV se restringe às propriedades biológicas e sorológicas (LIN et al. 1981a, 1981b, 1982, 1984). São conhecidos quatro sorotipos de CPSMV no Brasil, os quais podem ser diferenciados pela sorologia e gama de hospedeiros (LIN et al. 1981a, 1981b, 1982, 1984). De acordo com Hampton et al.
(1997), existem pelo menos nove sorotipos de CPSMV e um número desconhecido de variantes patogênicas. Contudo, em estudos de caracterização de sequências parciais e completas de genomas de isolados brasileiros de CPSMV, observou-se baixa variabilidade genética (ABREU et al. 2012; BESERRA et al. 2011; BOARI et al. 2021; TEIXEIRA et al. 2021).

A ocorrência de CABMV, CMV, CPMMV e CPSMV em feijão-fava resulta de forma natural em infecções mistas. As infecções duplas foram observadas entre CMV e CABMV (3,63\%), CMV e CPMMV (16,36\%), CABMV e CPMMV $(12,72 \%)$ e infecções triplas entre CMV e CABMV e CPMMV $(1,81 \%)$ (MEDEIROS et al. 2020). Percentuais semelhantes de infecção simples por CMV, CABMV e CPSMV, em feijão-caupi, foram relatadas por Santos et al. (1999), no Estado do Ceará.

\section{COWPEA MILD MOTTLE VIRUS (CPMMV)}

O CPMMV é considerado um patógeno emergente em culturas como soja e feijão-comum no Brasil (ZANARDO \& CARVALHO 2017). Em feijão-fava, esse vírus foi relatado ocorrendo naturalmente em plantas coletadas em regiões produtoras dos estados do Ceará e Piauí (MEDEIROS et al. 2020). O vírus foi detectado em 52,7\% (29/55) das amostras sintomáticas, incidência superior a outros vírus encontrados nas mesmas amostras como CABMV $(47,2 \%)$, CMV $(21,8 \%)$ e CPSMV $(1,81 \%)$.

Esse vírus foi identificado no Brasil em 1979 em feijão-comum, cultivar Jalo, nos estados do Paraná e São Paulo (COSTA et al. 1983). Também foi encontrado no estado de Pernambuco em feijão-comum e em plantas não cultivadas pertencentes a várias famílias botânicas, incluindo Fabaceae, Nyctaginaceae, Cleomaceae e Asteraceae (LAMAS et al. 2017). As principais espécies hospedeiras são da família Fabaceae, mas alguns isolados do vírus podem infectar experimentalmente espécies de outras famílias, como Chenopodiaceae e Solanaceae (ZANARDO \& CARVALHO 2017).

$O$ vírus é transmitido de forma não circulativa, não-persistente, pela mosca-branca B. tabaci, podendo ser adquirido e transmitido por períodos curtos, pelo menos 5 minutos de alimentação do inseto nas plantas. A eficiência de transmissão aumenta proporcionalmente com o maior tempo de aquisição e inoculação (MARUBAYASHI et al. 2010). Embora sejam predominantemente insetos tropi- 
cais, as moscas brancas são encontradas nas regiões mais quentes do mundo e várias delas também são pragas em casas de vegetação em regiões temperadas. Além de danos diretos às culturas causados pela alimentação, as moscas brancas também excretam açúcares que favorecem a proliferação de fungos (fumagina), e estes interferem na fotossíntese reduzindo o rendimento das plantas hospedeiras (NAVAS-CASTILLO et al. 2011). O CPMMV tem se tornado endêmico em muitas regiões, devido principalmente aos elevados níveis populacionais que as moscas-brancas atingem, promovendo a rápida disseminação do vírus. Além disso, as moscas brancas possuem um elevado número de plantas hospedeiras principalmente da família Fabaceae (ZANARDO \& CARVALHO 2017). A elevada incidência do CPMMV em feijão-fava, bem como em outras culturas como soja e feijão-comum reforçam a importância de se estabelecer estratégias efetivas de manejo e controle desse patógeno.

Diversos sintomas são provocados por CPMMV, que variam de acordo com o genótipo do hospedeiro e o isolado viral. Em feijão-fava o CPMMV induz sintomas sistêmicos de mosaico leve em folhas jovens a partir de 8 d.a.i. (Fig. 1C); aos 20 dias é observado mosaico amarelo em folhas jovens e velhas, bolhosidade e curvatura do limbo em folhas jovens. Em soja, uma gama de sintomas é observada a depender do isolado, que varia desde leve (folhas enrugadas, bolhosidade, mosaico e clareamento das nervuras) a severa (crestamento dos botões, nanismo, necrose de folhas e caule (ZANARDO et al. 2014).

A transmissão de CPMMV por semente depende do isolado. No Brasil, não foi observado a transmissão por sementes em feijão-caupi e feijão-comum, mas há um relato de transmissão de isolados brasileiros de CPMMV através de sementes de soja em incidência abaixo de 0,5\% (SILVA et al. 2020). Em outros países, como Venezuela e Uganda, foram relatadas taxas de transmissão de $40 \%$ em sementes de feijão-aspargo (Vigna unguiculata subsp. sesquipedalis) e $20,3 \%$ em feijão-caupi, respectivamente (AMAYO et al. 2012; BRITO et al. 2012). A transmissão do CPMMV através de sementes de feijão-fava não é conhecida.

Não foi observado agrupamento por região geográfica entre os isolados de CPMMV obtidos de feijão-fava com os isolados de soja, revelando não haver aparente separação geográfica entre eles, o que significa que há migração direta do patógeno promovida provavelmente pelo inseto vetor (MEDEIROS et al. 2020).

\section{OUTROS VÍRUS}

Pelo menos três vírus foram relatados em feijão-fava em outros países. O bean common mosaic necrosis virus (BCMNV) e o bean common mosaic virus (BCMV), ambos pertencentes ao gênero Potyvirus, família Potyviridae, foram relatados em Uganda e no Peru (SENGOOBA et al. 1997; MELGAREJO et al. 2007). Além disso, há relatos de infecções por begomovírus, que induzem sintomas de mosaico amarelo. No entanto, as espécies virais não foram identificadas (BIRD et al. 1972).

\section{CONTROLE}

No nordeste brasileiro, o feijão-fava é tradicionalmente plantado por agricultores familiares, os quais geralmente não adotam medidas de controle de doenças e pragas, favorecendo a ocorrência das viroses. Além disso, a elevada incidência de viroses em feijão-fava é favorecida pela safra prolongada dessa cultura, uma vez que permanece no campo por períodos de 6 a 8 meses. O tempo prolongado da cultura no campo, aliado ao cultivo concomitante com outras culturas como o feijão-caupi, feijão-comum ou soja, possibilita a sobrevivência dos insetos vetores e a disseminação dos patógenos, que muitas vezes têm hospedeiros em comum. Além disso, a baixa precipitação, observada em parte do período de cultivo do feijão-fava na região Nordeste, favorece a reprodução dos insetos vetores e, consequentemente, a incidência das viroses.

As estratégias de manejo das viroses em feijão-fava devem seguir àquelas adotadas para as demais leguminosas, isto é, serem preferencialmente preventivas, as quais tendem a funcionar quando baseadas em dados epidemiológicos. Variedades de feijão-fava resistentes aos principais vírus da cultura não estão comercialmente disponíveis. No Brasil, os únicos estudos de avaliação de resistência foram desenvolvidos por Melo et al. (2009) e Gusmão et al. (2009), que avaliaram a resistência de genótipos de feijão-fava contra o mosaico dourado e CABMV, respectivamente. No primeiro estudo, dos 72 genótipos expostos a infecção natural em campo, 18 apresentaram incidência média da doença abaixo de $5 \%$. Esse resultado tem que ser analisado com cautela, uma vez que os genótipos não foram inoculados em 
condições controladas. No segundo estudo, a resistência contra dois isolados de CABMV foi avaliada em 32 genótipos inoculados mecanicamente em ambiente protegido. Desses, cinco apresentaram reação de hipersensibilidade, ou seja, formação de pequenas lesões necróticas no local da inoculação, o que indicou a presença de gene(s) que confere $(\mathrm{m})$ ao feijão-fava imunidade ao CABMV (GUSMÃO et al. 2009). A partir do momento que as abordagens baseadas na resistência forem adotadas, pois permitem o manejo economicamente viável e ambientalmente correto, esta estratégia precisará ser utilizada juntamente com outras estratégias de manejo, visando à durabilidade da resistência.

Outra medida de controle importante a ser adotada para o controle do mosaico e mosaico dourado do feijão-fava, é o manejo das plantas espontâneas. Uma vez que os principais insetos vetores dos vírus que infectam feijão-fava são polífagos, isto é, podem colonizar e se reproduzir em numerosas espécies de plantas, patógenos como MaYSV, BGMV, CMV, CABMV, CPMMV, CPSMV e possivelmente outros, podem ser transmitidos a partir de plantas não cultivadas para a(s) espécie(s) cultivada(s). Na região sul do Estado do Piauí, é comum que produtores de feijão-fava não realizem a eliminação de plantas espontâneas, uma vez que muitas plantações estão localizadas em terrenos acidentados e pedregosos, o que dificulta a realização desse trato cultural. Além disso, o plantio de outras leguminosas no mesmo local e no mesmo período do ano funciona como ponte, permitindo que os vírus sejam intercambiados entre o feijão-fava e demais leguminosas.

O manejo dos insetos vetores para o controle das viroses em feijão-fava apresenta alguns desafios, uma vez que os únicos vetores conhecidos capazes de colonizar o feijão-fava são a mosca-branca B. tabacci e o afídeo A. craccivora (FORTES PORTELA et al. 2019; RAMOS-SOBRINHO et al. 2014). Mais estudos são necessários para conhecer os demais vetores de vírus nessa cultura. É sabido que em outras culturas como o feijão-comum e a soja, o manejo de populações da mosca-branca com inseticidas é pouco eficaz por diversos motivos, como a dificuldade de controlar grandes populações do inseto que possui muitas hospedeiras cultivadas e não cultivadas, pela elevada eficiência com que o inseto transmite os begomovírus e pela resistência do inseto a vários princípios ativos de inseticidas químicos (INOUE-NAGATA 2016).
O vazio sanitário adotado compulsoriamente por produtores de soja contribui com a redução na população dos insetos vetores que tem o feijão-fava como hospedeiro. Além disso, a produção de feijão-fava e outras leguminosas como o feijão-caupi é concentrada no primeiro semestre do ano, pois o feijão-fava é uma cultura de sequeiro, e é neste período que se concentram as chuvas no nordeste brasileiro. A ausência do feijão-fava e outras hospedeiras por alguns meses no segundo semestre do ano, período de estiagem na região, também favorece a redução das populações dos vetores (COSTA 1995).

\section{DOENÇAS CAUSADAS POR FUNGOS ANTRACNOSE}

A antracnose pode ser considerada a doença mais importante do feijão-fava (FEIJÓ et al. 2017; PAULA JÚNIOR et al. 2015). Por muitos anos, a antracnose do feijão-fava teve como único agente causal conhecido o fungo Colletotrichum truncatum (Schweinitz) Andrus \& W. D. Moore, o qual foi primeiramente descrito em associação com feijãofava nos Estados Unidos da América (EUA) (ANDRUS \& MOORE 1935). No entanto, em estudos de identificação e de patogenicidade de Colletotrichum spp. associados à antracnose do feijão-fava, identificaram-se mais seis espécies: $C$. cliviae e $C$. fructicola (SOUSA et al. 2018), C. brevisporum, C. lobatum, $C$. musicola e $C$. plurivorum, além de cinco novas linhagens (CAVALCANTE et al. 2019). Dentre estas espécies, $C$. truncatum foi a que apresentou maior prevalência (58\%), seguido de $C$. plurivorum (21\%), em propriedades de quatro estados do nordeste brasileiro (CAVALCANTE et al. 2019).

Os sintomas causados por $C$. truncatum em feijão-fava são mais severos que aqueles causados pelas demais espécies de Colletotrichum (CAVALCANTE et al. 2019; SOUSA et al. 2018). Surgem manchas avermelhadas no verso abaxial do limbo foliar, juntamente com lesões de mesma cor nas nervuras próximas. Com o avanço da doença, há seca e queda das folhas. Sintomas necróticos também são observados nos ramos, pecíolos e caule. Nas vagens, os principais sintomas são manchas de coloração marrom-escura e bordas vermelhoarroxeadas, que coalescem (Fig. 2).

Colletotrichum truncatum é eficientemente transmitido através de sementes de feijão-fava, alcançando uma taxa de transmissão de $83 \%$ quando as sementes são inoculadas artificialmente em 


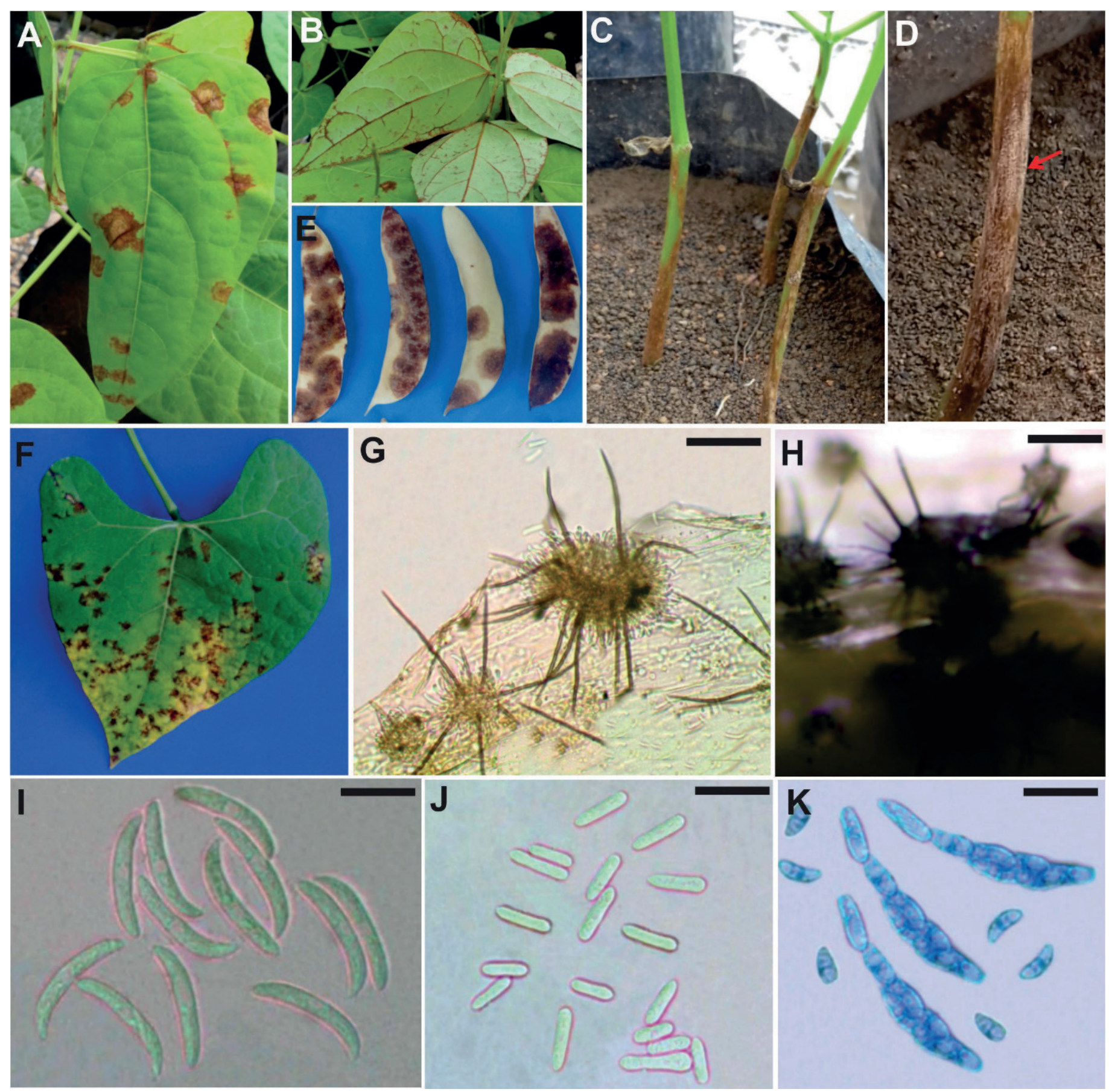

Figura 2. Colletotrichum spp. em feijão-fava. Sintomas em folhas e caules causados por C. truncatum (A-C). Massa de conídios (ver seta) (D). Manchas em vagens (E). Sintomas de mancha foliar causada por C. fructicola e C. cliveae (F). Setas (G). Esporodóqio em meio de cultura $\mathrm{CLA}(\mathrm{H})$. Conídios de $C$. truncatum (I). Conídios de C. fructicola (J). Ascos e ascósporos de C. cliviae (K). Barra: G, H=20 $\mu \mathrm{m} ; \mathrm{I}, \mathrm{J}, \mathrm{K}=40 \mu \mathrm{m}$.

Permissão de uso da imagem concedida por Springer Nature.

meios de cultura com diferentes potenciais hídricos (MOTA et al. 2019). Em sementes de feijão-fava naturalmente infectadas, a incidência máxima observada foi de $10 \%$, enquanto a incidência média entre as amostras foi próxima a $1 \%$. Não é sabido se o fungo pode permanecer latente após a queda dos cotilédones e ao longo do ciclo da cultura, induzindo, posteriormente, sintomas da antracnose.

Além de $C$. truncatum, outros 21 gêneros de fungos foram encontrados em sementes de feijão-fava naturalmente infectadas, dentre os quais importantes fungos fitopatogênicos como Fusarium spp., Macrophomina phaseolina, Rhizoctonia solani e Sclerotium sp. No entanto, $C$. truncatum foi o único representante do gênero Colletotrichum encontrado nas sementes (MOTA et al. 2017). A presença de $C$. truncatum e demais fungos de importância fitossanitária em sementes de feijão-fava, reforça a necessi- 
dade de medidas de tratamento de sementes visando reduzir a quantidade de inóculo primário.

Não existem fungicidas registrados para o controle de Colletotrichum spp. em feijão-fava no Brasil. No entanto, para o controle da antracnose causada por $C$. truncatum na cultura da soja são registrados fungicidas químicos à base de 26 princípios ativos, enquanto para a cultura do feijão-comum há um princípio ativo disponível (AGROFIT 2021). Além disso, outras estratégias de manejo da antracnose na cultura da soja incluem rotação de culturas, espaçamento amplo entre linhas, densidade de plantio apropriada, uso de sementes sadias e tratamento de sementes (BOUFLEUR et al. 2020).

Uma das medidas mais eficientes no manejo de doenças foliares - o uso de variedades resistentes, ainda não está disponível aos produtores brasileiros de feijão-fava. No entanto, acessos de feijão-fava resistentes a antracnose, causada por C. truncatum, foram identificados (BRITO 2017; CAVALCANTE et al. 2012; CARMO et al. 2015). Até o momento, oito acessos foram caracterizados como altamente resistentes, revelando potencial para serem usados em programas de melhoramento. Não foram identificados acessos imunes (BRITO 2017; CAVALCANTE et al. 2012; CARMO et al. 2015).

Outras medidas de manejo da antracnose no Brasil vêm sendo propostas, abrindo possibilidades para o manejo integrado. Produtos indutores de resistência a base de silicato de cálcio, argila silicatada e biomassa cítrica induziram resposta de defesa contra C. truncatum em 15 acessos de feijão-fava, demonstrando potencial de uso (GOMES \& NASClMENTO 2018). Outras fontes de silício, além de carbonato de cálcio, reduziram a severidade da antracnose pelo menos em $66 \%$ em plantas cultivadas em casa de vegetação e inoculadas com $C$. truncatum (NASCIMENTO et al. 2017).

Medidas isoladas de manejo, normalmente, não surtem efeito para o controle da antracnose do feijão-fava. Portanto, a integração de medidas necessita ser adotada para aumentar a eficiência no controle da doença. Entretanto, o pouco conhecimento da epidemiologia de Colletotrichum spp. associada à antracnose no feijão-fava pode resultar em manejo ineficiente da doença.

\section{PODRIDÃO DE CARVÃO}

A doença conhecida como podridão de carvão ou podridão cinzenta do caule, causada por
Macrophomina phaseolina (Tassi) Goid., foi relatada pela primeira vez em feijão-fava no Brasil por Sousa et al. (2017a). O patógeno é considerado um dos mais destrutivos nas regiões tropicais e subtropicais, principalmente nas condições ambientais de climas áridos e semiáridos do Nordeste brasileiro. Essa doença tem se destacado em muitas partes do mundo, principalmente pela grande dificuldade de controle e por provocar redução no estande das plantas no campo, baixa qualidade de sementes, morte e maturação precoce das plantas (LODHA \& MAWAR 2020; MOTA et al. 2019).

Embora apenas M. phaseolina tenha sido relatada em feijão-fava (SOUSA et al. 2017a), não se pode descartar a associação de outras espécies de Macrophomina com a doença, uma vez que $M a-$ crophomina pseudophaseolina e Macrophomina euphorbiicola estão presentes nos solos brasileiros e associados a doenças em diversas culturas como o feijão-caupi, amendoim (Arachis hypogaea L.), algodão (Gossypium hirsutum L.), mamona (Ricinus communis L.) e com sementes de Jatropha curcas L. (MACHADO et al. 2019; SALES JÚNIOR et al. 2020) e M. pseudophaseolina em plantas espontâneas (NEGREIROS et al. 2019). A rápida identificação de Macrophomina spp. em diversas espécies botânicas tem sido possível pelo desenvolvimento de oligonucleotídeos específicos para três espécies de Macrophomina: M. phaseolina, M. pseudophaseolina e M. euphorbiicola (SANTOS et al. 2020).

Macrophomina phaseolina é patogênico a mais de 500 espécies de plantas e responsável pelos baixos índices de rendimento de culturas de grande importância econômica como feijões, soja, algodoeiro e milho (GUPTA et al. 2012). Os restos de cultura são importantes fontes de inóculo primário e as sementes contaminadas a principal fonte de disseminação do fungo. Em sementes de feijão-fava, incidência máxima de 18,2\% (média 1,5\%) foi encontrada em 34 amostras de sementes coletadas em pequenos produtores rurais e feiras-livres em cidades da região do Nordeste do país (MOTA et al. 2017). Sementes de feijão-fava inoculadas artificialmente em meios de cultura com diferentes potenciais hídricos apresentaram taxa de transmissão de 83\% (MOTA et al. 2019). Esses dados revelam a elevada capacidade de $M$. phaseolina ser disseminada por sementes.

A severidade da doença causada por $M$. phaseolina pode variar dependendo do órgão e do 
estádio de desenvolvimento da planta infectada, e das condições ambientais. Em campo, redução nos níveis de germinação e emergência, podridão de sementes, e mortalidade de plântulas, são sintomas provocados pelo patógeno (KAUR et al. 2012). Em feijão-fava, os sintomas comuns que podem ser observados são: podridão de sementes, tombamento (pré- e pós-emergência), necroses negras nos cotilédones, epicótilo e hipocótilo, podridão do caule e da haste, podridão da raiz e murcha (Fig. 3). As lesões nos cotilédones, geralmente, são seguidas da morte da plântula devido a destruição do sistema vascular. As plantas que conseguem escapar da infecção precoce, podem ser infectadas em outros estádios de desenvolvimento, o que pode causar a queda das folhas e seca. Em plantas adultas é frequentemente observada a presença de lesões fusiformes nas hastes, com coloração acinzentada; os picnídios podem ser observados em caules e ramos como pequenas pontuações negras dispersas entre as lesões; plantas adultas com altos níveis de severidade da doença podem apresentar murcha e a consequente morte. Os fatores que levam à morte das raízes e do caule em diversas espécies botânicas são a obstrução dos vasos do xilema e a ação patogênica do fungo, com produção de enzimas e toxinas que necrosam o tecido (MARQUEZ et al. 2021).

Considerando-se fatores do patógeno como a facilidade de disseminação e a longevidade, além de fatores que fragilizam a estabilidade produtiva da cultura como pouca atenção dada por parte dos órgãos de pesquisa e extensão, baixo nível tecnológico de produção e manejo fitossanitário, a doença configura-se como um problema crescente para a produção do feijão-fava.

O uso de variedades de feijão-fava resistentes a M. phaseolina não é uma opção de manejo disponível para os produtores. A busca por acessos de feijão-fava resistentes revelou instabilidade da resistência, uma vez que a reação de resistência dos acessos considerados resistentes variou conforme o isolado fúngico testado (GARCÍA et al. 2019). Considerando a melhor estabilidade da resistência contra sete isolados de $M$. phaseolina, apenas um acesso (UFPI 908), dentre 37 acessos, expressou resistência moderada, indicando a dificuldade na obtenção de genótipos com resistência a um patógeno que apresenta elevada agressividade (GARCÍA et al. 2019).

Não existem fungicidas registrados para o controle de $M$. phaseolina em feijão-fava no Brasil. Para o controle de M. phaseolina em feijão-comum, são registrados apenas fungicidas químicos à base de carboxanilida + dimetilditiocarbamato, fenilpirrol e triazol, além do fungicida microbiológico do fungo antagonista Trichoderma harzianum (AGROFIT 2021), os quais são recomendados para o tratamento de sementes.

\section{OUTRAS DOENÇAS FÚNGICAS}

Murcha de fusário - Há um registro de Fusarium falciforme (FSSC $3+4$ ) provocando podridão de raiz e murcha em feijão-fava no Estado do Piauí (SOUSA et al. 2017b). F. falciforme é uma espécie clinicamente importante, que pode ser comum em ambientes agrícolas, inclusive associado à soja (CHITRAMPALAM \& NELSON 2016) e outras culturas importantes como cebola, mamão, tomate, milho e feijão. A eficácia de medidas de controle não foram avaliadas em feijão-fava.

Podridão do colo - Doença causada por Sclerotium rolfsii Sacc. Os sintomas da doença assemelham-se aos observados em outras fabáceas; aparecem inicialmente no colo da planta, como manchas escuras e encharcadas, estendendose pela raiz principal e produzindo podridão. É comum a ocorrência de micélio fúngico branco, e o consequente aparecimento de escleródios-brancos quando imaturos, tornando-se marrom-escuros na maturidade (AMORIM et al. 2016). Dois genótipos de feijão-fava, dentre 50 avaliados, apresentaram elevada resistência contra 11 isolados de S. rolfsii, constituindo fontes promissoras de resistência à podridão do colo (SILVA et al. 2004).

\section{CONSIDERAÇÕES FINAIS}

O feijão-fava é uma cultura pouco explorada economicamente quando comparada a outros feijões. Consequentemente, os estudos de etiologia, epidemiologia e manejo são encontrados em menor número, muito embora essa realidade venha se modificando a partir dos estudos publicados na última década. Esforços vêm sendo feitos por diferentes grupos de pesquisa brasileiros para revelar os agentes causais de doenças causadas por vírus e fungos fitopatogênicos, bem como para identificar genótipos resistentes aos principais patógenos da cultura.

Espera-se que nos próximos anos sejam desenvolvidas variedades de feijão-fava com características agronômicas e morfológicas desejáveis, 

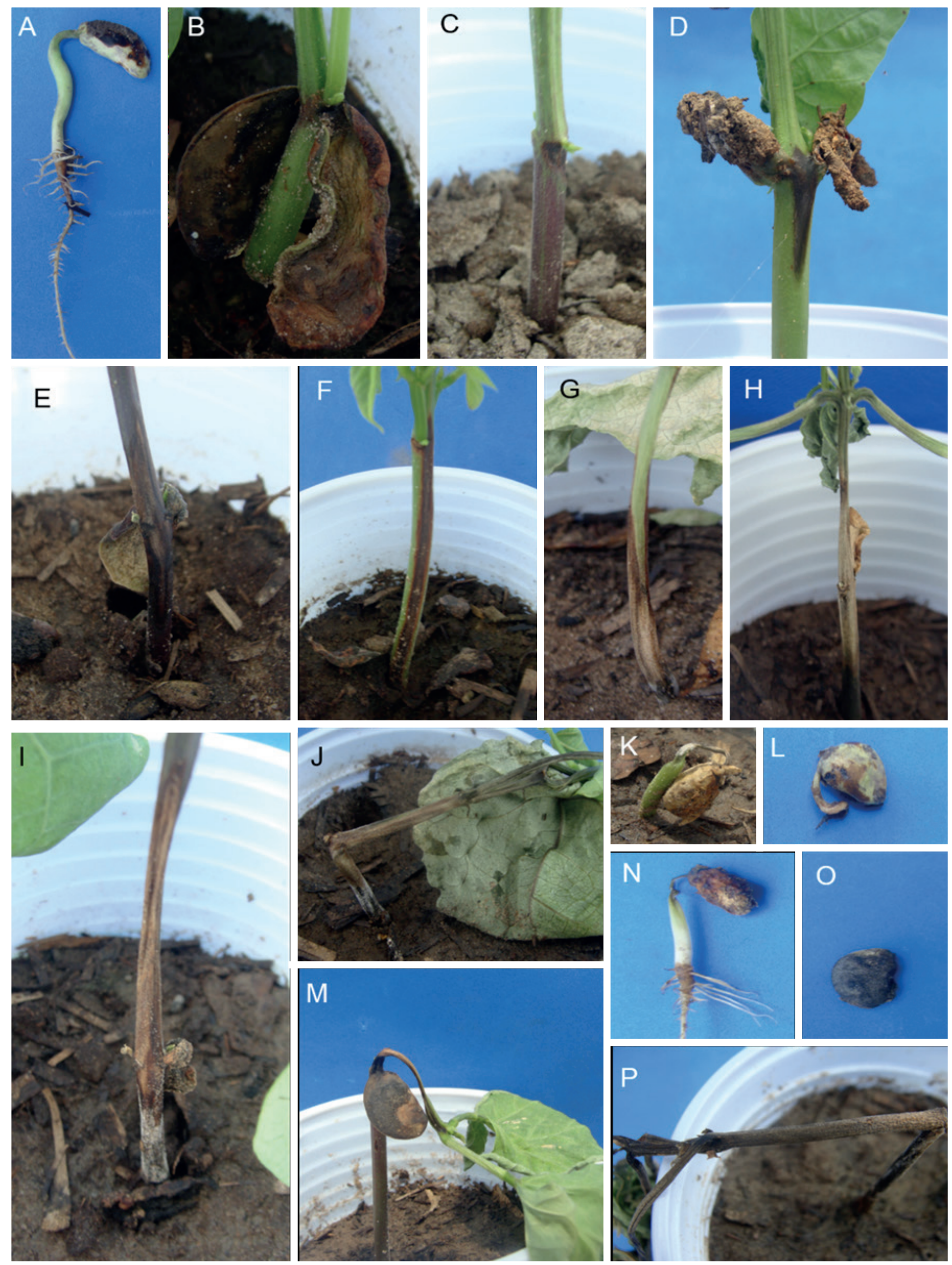

Figura 3. Sintomas de Macrophomina phaseolina em feijão-fava. Necrose do cotilédone (A, B), necrose do colo $(C)$, necrose na inserção dos cotilédones (D), necrose do hipocótilo e caule $(E, F, G)$, seca da plântula $(H)$, estrangulamento do caule (I), tombamento (J, K, M, N, P), podridão de sementes ( $L, O)$. Fonte: autores. 
como crescimento determinado e ciclo curto, fazendo que seus cultivos sejam expandidos no território nacional. Além disso, aspectos da biologia dos patógenos como o conhecimento da taxa de transmissão viral por sementes, dos vetores envolvidos na transmissão viral, a avaliação de perdas ocasionadas pelas doenças virais e fúngicas, bem como a eficiência de fungicidas nesta cultura ainda precisam ser esclarecidos.

\section{REFERÊNCIAS}

ABREU EFM, TINICO MLP, ANDRADE EC, ARAGÃO FJL (2012). Diversity among isolates of Cowpea severe mosaic virus infecting cowpeas in northeastern Brazil. Genetics and Molecular Research 11: 3146-3153. (http://dx.doi.org/10.4238/2012. September.3.3).

AGROFIT (2021). Sistemas de agrotóxicos fitossanitários. Available at: http://extra net.agric ultura. gov.br/agrof it_cons/princ ipal_agrof it_cons. Accessed on August 09, 2021.

AMAYO R, ARINAITWE AB, MUKASA SB, TUSIIME $G$, KYAMANYWA $S$, RUBAIHAYO PR, EDEMA R (2012). Prevalence of viruses infecting cowpea in Uganda and their molecular detection. African Journal of Biotechnology 11: 14132-14139. (https://doi.org/10.5897/AJB11.398).

AMORIM L, REZENDE JAM, CAMARGO LEA (Eds.) (2016). Manual de Fitopatologia Vol. 2. - Doenças das plantas cultivadas. $5^{a}$ edição. São Paulo: Agronômica Ceres.

ANDRADE GP, SILVA JL, PIO-RIBEIRO G, ALVES JÚNIOR M, RODRIGUES AAC (2001). Infecção natural de fava com CABMV em Itambé e Terezinha no Estado de Pernambuco. In: 34을 Congresso Brasileiro de Fitopatologia, Resumos...São Pedro, SP. p. 511-512.

ANDRUS CF, MOORE WD (1935). Colletotrichum truncatum (Schw.), n. comb., on garden and lima beans. Phytopathology 25:121-125.

ANJOS JRN, LIN MT (1984). Bud blight of soybeans caused by Cowpea severe mosaic virus in Central Brazil. Plant Disease 68: 405-407.

BARROS DR, ALFENAS-ZERBINI P, BESERRA JÚNIOR JEA, ANTUNES TFS, ZERBINI FM (2011). Comparative analysis of the genomes of two isolates of Cowpea aphid-borne mosaic virus (CAB$\mathrm{MV}$ ) obtained from different hosts. Archives of Virology 156: 1085-1091. (https://doi.org/10.1007/ s00705-011-0962-7).
BESERRA JR JEA, ANDRADE EC, CAMARÇO RFRA, NASCIMENTO AKQ, LIMA JAA (2011). Sequence variability in the coat protein gene of Cowpea severe mosaic virus isolates from northeastern Brazil. Tropical Plant Pathology 36: 121-124. (http://dx. doi.org/10.1590/S1982-56762011000200009).

BIRD J, PEREZ JE, ALCONERO R, VAKILI NG, MELENDEZ PL (1972). A whitefly-transmitted golden-yellow mosaic virus of Phaseolus lunatus in Puerto Rico. Journal of Agriculture of the University of Puerto Rico 56: 64-74.

BOARI AJ, QUADROS AFF, KAUFFMANN CM, PANTOJA KFC, GOMES JÚNIOR RA, FREIRE FILHO FR, OLIVEIRA RP, CORDOVIL GA, GAVINHO BES, KITAJIMA EW, BLAWID R, NAGATA T (2021). Near-complete genome sequence of cowpea severe mosaic virus in South America and reduced yardlong bean production due to the viral infection. Tropical Plant Pathology. (https://doi. org/10.1007/s40858-021-00420-w).

BOCK KR, CONTI M (1974). Cowpea aphid-borne mosaic virus. Kew: CMI/AAB, 1974. Descriptions of Plant Viruses 134. Available at: https://dpvweb. net/dpv/showdpv/?dpvno=134. Accessed on June 12, 2021.

BOOKER HM, UMAHARAN P, MCDAVID CR (2005). Effect of Cowpea severe mosaic virus on growth characteristics and yield of cowpea. Plant Disease 89: 515-520. (https://doi.org/10.1094/PD-890515).

BOUFLEUR TR, CIAMPI-GUILLARDI M, TIKAMI I, ROGÉRIO F, THON MR, SUKNO SA, MASSOLA JÚNIOR NS, BARONCELLI R (2021). Soybean anthracnose caused by Colletotrichum species: Current status and future prospects. Molecular Plant Pathology 22: 393-409. (https://doi.org/10.1111/ mpp.13036).

BRITO M, FERNÁNDEZ-RODRÍGUEZ T, GARRIDO MJ, MEJÍAS A, ROMANO M, MARYS E (2012). First report of Cowpea mild mottle carlavirus on yardlong bean (Vigna unguiculata subsp. sesquipedalis) in Venezuela. Viruses 4: 38043811. (https://doi.org/10.3390/v4123804).

CARVALHO EMS, BESERRA JEA JR., BARGUIL BM (2015). Lima bean diseases. In: Lopes ACA, Gomes RLF, Ferreira ASA (Ed) Phaseolus lunatus: Diversity, growth and production. New York: Nova Science Publishers, pp. 113-133.

CASTILLO-URQUIZA GP, BESERRA JEA, BRUCKNER FP, LIMA ATM, VARSANI A, ALFENAS-ZERBI- 
NI P, ZERBINI FM (2008). Six novel begomoviruses infecting tomato and associated weeds in Southeastern Brazil. Archives of Virology 153: 1985-1989. (https://doi.org/10.1007/s00705008-0172-0).

CAVALCANTE GR, BARGUIL BM, VIEIRA WA, LIMA WG, MICHEREFF SJ, DOYLE VP, CÂMARA MP (2019). Diversity, prevalence, and virulence of Colletotrichum species associated with Lima bean in Brazil. Plant Disease 103: 1961-1966. (https:// doi.org/10.1094/PDIS-11-18-2002-RE).

CHEL-GUERREIRO L, DOMINGUEZ-MAGAÑA $M$, MARTÍNEZ-AYALA A, DÁVILA-ORTIZ G, BETANCUR-ANCONA D (2012). Lima bean (Phaseolus lunatus L.) protein hydrolysates with ACE-I inhibitory activity. Food and Nutrition Sciences 3: 511521. (https://doi.org/10.4236/fns.2012.34072).

CHITRAMPALAM P, NELSON B (2016). Multilocus phylogeny reveals an association of agriculturally important Fusarium solani species complex (FSSC) 11, and clinically important FSSC 5 and FSSC $3+4$ with soybean roots in the north central United States. Antonie van Leeuwenhoek 109: 335-347. (https://doi.org/10.1007/s10482-015-0636-7).

COELHO LM, PIO-RIBEIRO G, LIMA JA, BURITY HA, MARIANO RLR, KITAJIMA EW, PADOVAN IP (1992). Caracterização de um isolado pernambucano do vírus do mosaico severo do caupi. Fitopatologia Brasileira 17: 331-335.

COSTA AS (1965). Three whitefly-transmitted virus diseases of beans in São Paulo, Brazil. Plant Protection Bulletin 13: 121-130.

COSTA CL, LIN MT, KITAJIMA EW, SANTOS AA, MESQUITA RCM, FREIRE FRF (1978). Cerotoma arcuata (Oliv.) um crisomelídeo vetor do mosaico da Vigna no Brasil. Fitopatologia Brasileira 3: 81-82.

COSTA AS, GASPAR JO, VEJA J (1983). Mosaico angular do feijoeiro Jalo causado por um carlavírus transmitido pela mosca branca Bemisia tabaci. Fitopatologia Brasileira 8: 325-337.

COSTA AF, MATOS FSA, SANTOS OR, KITAJIMA EW, MEYER MC (1991). Um comovírus isolados de planta obtida de semente de Phaseolus lunatus, colhida em Jataí, GO. Fitopatologia Brasileira 16: 25.

COSTA AF (1995). Doenças causadas por vírus em hortaliças leguminosas. Doenças de hortaliças. Informe Agropecuário 17: 75-85.

EIRAS M, BOARI AJ, COLARICCIO A, CHAVES ALR,
BRIONES MRS, FIGUEIRA AR, HARAKAVA $R$ (2004). Characterization of isolates of the Cucumovirus Cucumber mosaic virus present in Brazil. Journal of Plant Pathology 86: 61-69.

FARIA JC, MAXWELL DP (1999). Variability in geminivirus isolates associated with Phaseolus spp. in Brazil. Phytopathology 89: 262-268. (https://doi. org/10.1094/PHYTO.1999.89.3.262).

FEIJÓ FM, SILA WC, ASSUNÇÃO IPA, MARTINS RB, MICHEREFF SJ, LIMA GSA (2017). Análise de escala diagramática para avaliação da severidade da antracnose das vagens de feijão-fava. Ciência Agrícola 15:43-51. (https://doi.org/10.28998/rca. v15i1.2677).

FONTENELE RS, POPPIEL R, MATOS VORL, COSTA F, FARIA JC, RIBEIRO SG (2016). First report of Macroptilium yellow spot virus in Desmodium glabrum in Brazil. Plant Disease 100: 657 (http:// dx.doi.org/10.1094/PDIS-09-15-1086-PDN).

FORTES PORTELA GL, SILVA PRR, GIRÃO FILHO JE, PÁDUA LEM, MELO JÚNIOR LC (2019). Silicon as resistance inducer in to control black aphid Aphis craccivora Koch, 1854 in Phaseolus lunatus lima beans. Arquivos do Instituto Biológico 86: e0512018. (https://doi.org/10.1590/18081657000512018).

GARCÊZ RM, CHAVES ALR, EIRAS M, MELETTI LMM, AZEVEDO FILHO JA, SILVA LA, COLARICCIO A (2015). Survey of aphid population in a yellow passion fruit crop and its relationship on the spread Cowpea aphid-borne mosaic virus in a subtropical region of Brazil. SpringerPlus 4: 537. (https://doi.org/10.1186/s40064-015-1263-5).

GARCÍA MFM, SOUZA ES, SILVA JDD, MELO MP, MOTA JM, ALMEIDA NETO AD, GOMES RLF, BESERRA JR JEA (2019). Reação de genótipos de feijão-fava a Macrophomina phaseolina. Summa Phytopathologica 45: 11-17. (http://dx.doi. org/10.1590/0100-5405/185340).

GASPARIN MDG, BIANCHINI A, SOUTO ER, GASPAR JO, ALMEIDA AMR, KITAJIMA EW (2005). Detecção do Southern bean mosaic virus no Paraná, e separação do Bean rugose mosaic virus em feijoeiro. Fitopatologia Brasileira 30: 75-78. (http://dx. doi.org/10.1590/S0100-41582005000100013).

GOMES RLF, COSTA MF, PEREIRA AA, BAJAY MB, VIANA JPG, VALENTE SES, LOPES ACA, ZUCCHI MI, PINHEIRO JB (2020). A lima bean core collection based on molecular markers. Scientia Agricola 77: 1-8. (https://doi.org/10.1590/1678- 
992x-2018-0140).

GOMES RSS, NASCIMENTO LC (2018). Induction of resistance to Colletotrichum truncatum in lima bean. Arquivos do Instituto Biológico 85: e0022018. (http://dx.doi.org/10.1590/18081657000022018).

GOMES RLF, SOARES CA, GÂNDARA FC, BURLE $M B$ (2015). Aspects of crop and socioeconomic management of the lima bean within Northeastern Brazil. In: Lopes ACA, Gomes RLF, Ferreira ASA (Ed) Phaseolus lunatus: Diversity, growth and production. New York: Nova Science Publishers, pp. 135-151.

GUPTA GK, SHARMA SK, RAMTEKE R (2012). Biology, epidemiology and management of the pathogenic fungus Macrophomina phaseolina (Tassi) Goid with special reference to charcoal rot of soybean (Glycine max (L.) Merrill). Journal of Phytopathology 160: 167-180.

GUSMÃO LO, MELO EA, ASSUNÇÃO IP, LIMA GSA (2009). Reaction of lima bean genotypes to cowpea aphid-born virus. In: XX National Meeting of Virology, Resumos... Brasília, DF. p. 259-260.

HAMPTON RO, THOTTAPPILLY G, ROSSEL HW (1997). Viral diseases of cowpea and their control by resistance-conferring genes. In: Singh BB, Mohan RAJ, Dashiell KE, Jackai LEN (Eds). Advances in cowpea research. Copublication of International Institute of Tropical Agriculture (IITA) and Japan International Research Center for Agricultural Science (JIRCAS). IITA, Ibadan, Nigeria. pp. 159-175.

IBGE (2020). Banco de dados agregados: pesquisa: Produção Agrícola Municipal. Culturas temporárias. 2019. (BR). Available at: https://sidra.ibge. gov.br/pesquisa/pam/tabelas. Accessed on June 12, 2021.

INOUE-NAGATA AK, LIMA MF, GILBERTSON RL (2016). A review of geminivirus (begomovirus) diseases in vegetables and other crops in Brazil: current status and approaches for management. Horticultura Brasileira 34: 8-18. (http://dx.doi. org/10.1590/S0102-053620160000100002).

KAUR S, DHILLON GS, BRAR SK, VALLAD GE, CHAND R, CHAUHAN VB (2012). Emerging phytopathogen Macrophomina phaseolina: biology, economic importance and current diagnostic trends. Critical Reviews in Microbiology 38: 136-151. (https:// doi.org/10.3109/1040841X.2011.640977).

KITAJIMA EW, ALCÂNTARA BK, MADUREIRA PM, ALFENAS-ZERBINI P, REZENDE JAM, ZERBINI
FM (2008). A mosaic of beach bean (Canavalia rosea) caused by an isolate of Cowpea aphid-borne mosaic virus (CABMV) in Brazil. Archives of Virology 153: 743-747. (https://doi.org/10.1007/ s00705-008-0052-7).

LIMA JAA, SILVEIRA LFS, OLIVEIRA JP (1989). Não-transmissibilidade de Cowpea severe mosaic virus por sementes de Vigna unguiculata cvs. Pitiuba e Seridó. Fitopatologia Brasileira 14: 50-55.

LIN MT, HILL JH, KITAJIMA EW, COSTA CL (1984). Two novel serotypes of Cowpea severe mosaic virus. Plant Disease 74: 581-585.

LIN MT, ANJOS RN, RIOS GP (1982). Cowpea severe mosaic virus in five legumes in Central Brazil. Plant Disease 66: 67-70.

LIN MT, ANJOS RN, RIOS GP (1981a). Serological grouping of Cowpea severe mosaic virus isolates from Central Brazil. Plant Disease 71: 435-438.

LIN MT, KITAJIMA EW, RIOS GP (1981b). Detecção serológica de dois vírus previamente desconhecidos em caupi (Vigna unguiculata) no Brasil Central. Fitopatologia Brasileira 6: 73-85.

LODHA S, MAWAR R (2020). Population dynamics of Macrophomina phaseolina in relation to disease management: A review. Journal of Phytopathology 168: 1-17. (https://doi.org/10.1111/ jph.12854).

LONG R, TEMPLES S, MEYER R, SCHWANKL L, ODFREY L, CANEVARI M, ROBERTS P (2014). Lima Bean Production in California. University of California, ANR, n. 8505, p. 25. (http://doi. org/10.3733/ucanr.8505).

MACHADO AR, PINHO DB, SOARES DJ, GOMES AAM, PEREIRA OL (2019). Bayesian analyses of five gene regions reveal a new phylogenetic species of Macrophomina associated with charcoal rot on oilseed crops in Brazil. European Journal of Plant Pathology 153: 89-100. (https://doi. org/10.1007/s10658-018-1545-1).

MARQUEZN, GIACHEROML,DECLERCKS, DUCASSE DA (2021). Macrophomina phaseolina: general characteristics of pathogenicity and methods of control. Frontiers in Plant Science 12: 634397. (https://doi.org/10.3389/fpls.2021.634397).

MARUBAYASHI JM, YUKI VA, WUTKE EB (2010). Transmissão do Cowpea mild mottle virus pela mosca branca Bemisia tabaci biótipo B para plantas de feijão e soja. Summa Phytopathologica 36: 158-160. (https://doi.org/10.1590/S010054052010000200009). 
MEDEIROS LSA, OLIVEIRA IA, KITAJIMA EW, EIRAS M PEREIRA HJ, RIBEIRO SG, MATOS KS, BESERRA JÚNIOR JEA (2020). A survey of RNA genome viruses in Lima bean crops of Northeastern Brazil. Bragantia 79: 407-416. (https://doi.org/10.1590/1678-4499.20190467).

MELGAREJO TA, LEHTONEN MT, FRIBOURG CE, RÄNNÄLI M, VALKONEN JP (2007). Strains of $B C M V$ and BCMNV characterized from lima bean plants affected by deforming mosaic disease in Peru. Archives of Virology 152: 1941-1949. (https://doi.org/10.1007/s00705-007-1008-z).

MELO EA, SILVA NETO JR, GUSMÃO LO, SILVA SJC, ASSUNÇÃO IP, LIMA GSA (2009). Incidence of golden mosaic in lima bean genotypes. In: XX National Meeting of Virology, Resumos... Brasília, DF. p. 246.

MORAES LA, MULLER C, BUENO RCOF, SANTOS A, BELLO VH, DE MARCHI BR, WATANABE LFM, MARUBAYASHI JM, SANTOS BR, YUKI VA, TAKADA HM, DE BARROS DR, NEVES CG, DA SILVA FN, GONÇALVES MJ, GHANIM M, BOYKIN L, PAVAN MA, KRAUSE-SAKATE R (2018). Distribution and phylogenetics of whiteflies and their endosymbiont relationships after the Mediterranean species invasion in Brazil. Scientific Reports 8: 14589. (https://doi.org/10.1038/s41598-01832913-1).

MORALES FJ (2006). History and current distribution of begomoviruses in Latin America. Advances in Virus Research 67: 127-162. (https://doi. org/10.1016/S0065-3527(06)67004-8).

MOSES O, OLAWUNI I, JO I (2012). The proximate composition and functional properties of full-fat flour and protein isolate of Lima Bean (Phaseolus lunatus L.). Open Access Scientific Reports 1: 1-5. (http://dx.doi.org/10.4172/scientificreports.349).

MOTA JM, MELO MP, GARCÍA MFM, SOUSA ES, SOUSA EMJ, BARGUIL BM, BESERRA JR JEA (2019). Transmission of Colletotrichum truncatum and Macrophomina phaseolina by lima bean seeds. Summa Phytopathologica 45: 33-37. (https://doi.org/10.1590/0100-5405/180868).

NASCIMENTO AD, FEIJÓ FM, ALBUQUERQUE AW, ASSUNÇÃO IP, LIMA GSA, REIS LS (2017). Severidade da antracnose do feijão-fava afetada por doses de cálcio e fontes de silício. Ciência Agrícola 15: 61-68.

NASCIMENTO AVS, SANTANA EN, BRAZ ASK, ALFENAS PF, PIO-RIBEIRO G, ANDRADE GP,
CARVALHO MG, ZERBINI FM (2006). Cowpea aphid-borne mosaic virus (CABMV) is widespread in passionfruit in Brazil, and causes passionfruit woodiness disease. Archives of Virology 151: 1797-1809. (https://doi.org/10.1007/s00705006-0755-6).

NAVAS-CASTILLO J, FIALLO-OLIVÉ E, SÁNCHEZ-CAMPOS E (2011). Emerging virus diseases transmitted by whiteflies. Annual Review of Phytopathology 49: 219-248. (https://doi.org/10.1146/ annurev-phyto-072910-095235).

NEGREIROS AMP, SALES JÚNIOR R, NAAMA ML, MELO JA, MICHEREFF SJ, AMBRÓSIO MMQ, MEDEIROS HLS, ARMENGOL J (2019). Identification and pathogenicity of Macrophomina species collected from weeds in melon fields in Northeastern Brazil. Journal of Phytopathology 167: 326-337. (https://doi.org/10.1111/jph.12801).

OLIVEIRA CRR, FREIRE FILHO FR, NOGUEIRA MSR, BARROS GB, EIRAS M, RIBEIRO VQ, LOPES ACA (2012). Reação de genótipos de feijão-caupi revela resistência às coinfecções pelo Cucumber mosaic virus, Cowpea aphid-borne mosaic virus e Cowpea severe mosaic virus. Bragantia 71: 59-66. (https:// doi.org/10.1590/S0006-87052012005000007).

PAULA JÚNIOR TJ, SILVA MB, VIEIRA RF (1995). Doenças causadas por fungos em hortaliças leguminosas. Informe Agropecuário 17: 63-71.

PIO-RIBEIRO G, PAPPU SS, PAPPU HR, ANDRADE GP, REDDY DVR (2000). Occurrence of Cowpea aphid-borne mosaic virus in peanut in Brazil. Plant Disease 84: 760-766. (https://doi.org/10.1094/ PDIS.2000.84.7.760).

RAMOS-SOBRINHO R, XAVIER CAD, PEREIRA HMB, LIMA GSA, ASSUNÇÃO IP, MIZUBUTI ESG, DUFFY S, ZERBINI FM (2014). Contrasting genetic structure between two begomoviruses infecting the same leguminous hosts. Journal of General Virology 95: 2540-2552. (https://doi.org/10.1099/ vir.0.067009-0).

SALES JÚNIOR R, SILVA NETO AN, NEGREIROS AMP, GOMES TRR, AMBRÓSIO MMQ, ARMENGOL J (2020). Pathogenicity of Macrophomina species collected from weeds in cowpea. Revista Caatinga 33: 395-401. (https://doi.org/10.1590/ 1983-21252020v33n212rc).

SANTOS KM, LIMA GS, BARROS APO, MACHADO AR, SOUZA-MOTTA CM, CORREIA KC, MICHEREFF SJ (2020). Novel specific primers for rapid identification of Macrophomina species. Europe- 
an Journal of Plant Pathology 156: 1213-1218. (https://doi.org/10.1007/s10658-020-01952-8).

SANTOS D, COLLETT FMF, MENDES JEMF, WANDERLEY-JUNIOR JSA (2002). Produtividade $\mathrm{e}$ morfologia de vagens e sementes de variedades de fava no Estado da Paraíba. Pesquisa Agropecuária Brasileira 37: 1407-1412. (https://doi. org/10.1590/S0100-204X2002001000008).

SANTOS FML, LIMA JAA, SANTOS AA, BARRETO PD (1999). Infecções simples e múltiplas de vírus em caupi no Ceará. Fitopatologia Brasileira 24: 518-522.

SENGOOBA TN, SPENCE NJ, WALKEY DGA, ALLEN DJ, LANA AF (1997). The occurrence of bean common mosaic necrosis virus in wild and forage legumes in Uganda. Plant Pathology 46: 95-103. (https://doi.org/10.1046/j.1365-3059.1997.d0112.x).

SILVA FB, MULLER C, BELLO VH, WATANABE LFM, DE MARCHI BR, FUSCO LM, RIBEIRO-JUNIOR $M R$, MINOZZI GB, VIVAN LM, TAMAI MA, FARIAS JR, NOGUEIRA AM, SARTORI MMP, KRAUSESAKATE R (2020). Effects of cowpea mild mottle virus on soybean cultivars in Brazil. PeerJ 8: e9828 (https://doi.org/10.7717/peerj.9828).

SILVA MA, LIMA GSA, ASSUNÇÃO IP, LARANJEIRA FF, MICHEREFF SJ (2015). Progresso e arranjo espacial do mosaico dourado em fava. Revista Caatinga 28: 19-27.

SILVA SJC, CASTILLHO-URQUIZA GP, HORA-JÚNIOR BT, ASSUNÇÃO IP, LIMA GSA, PIO-RIBEIRO G, MIZUBUTI ESG, ZERBINI FM (2012). Species diversity, phylogeny and genetic variability of begomovirus populations infecting leguminous weeds in northeastern Brazil. Plant Pathology 61: 457-467. (https://doi.org/10.1111/ j.1365-3059.2011.02543.x).

SILVA JA, OLIVEIRA MG, SOUZA LT, ASSUNÇÃO IP, LIMA GA, MICHEREFF SJ (2014). Reação de genótipos de feijão-fava a Sclerotium rolfsii. Horticultura Brasileira 32: 98-101. (https://doi. org/10.1590/S0102-05362014000100016).

SOUSA ES, SILVA JRA, ASSUNÇÃO IP, MELO MP, FEIJÓ FM, MATOS KS, BESERRA JEA (2018). Colletotrichum species causing anthracnose on lima bean in Brazil. Tropical Plant Pathology 43: 78-84. (https://doi.org/10.1007/s40858-017-0182-0).
SOUSA ES, MELO, MP, PIRES LL, SILVA BA, GARCÍA MEM, SOUSA EMJ, MOTA JM, BESERRA JR JEA (2017a). First report of Macrophomina phaseolina causing charcoal rot in Lima bean (Phaseolus lunatus) in Brazil. Plant Disease 101: 1551. (https:// doi.org/10.1094/PDIS-11-16-1661-PDN).

SOUSA ES, MELO MP, MOTA JM, SOUSA EMJ, MATOS KS, BESERRA JR JEA (2017b) First report of Fusarium falciforme (FSSC $3+4$ ) causing root rot in Lima bean (Phaseolus lunatus L.) in Brazil. Plant Disease 101: 1954. (https://doi.org/10.1094/ PDIS-05-17-0657-PDN).

TEIXEIRA KJML, SOUZA CASCARDO R, LEAL LL, ZERBINI FM, BESERRA JEA JR (2021). First complete genome sequence of an isolate of cowpea severe mosaic virus from South America. Virus Genes 57: 238-241. (https://doi.org/10.1007/ s11262-021-01831-2).

VIEIRA M (2017). Caracterização morfoagronômica e seleção de acessos de feijão fava resistente a Colletotrichum truncatum. Masters Dissertation, Universidade Federal do Piauí, Teresina, Piauí, Brasil.

VIEIRA RFA (1992). A cultura de feijão-fava. Informe Agropecuário16: 30-37.

WANG Y, GABA V, YANG J, PALUKAITIS P, GAL-ON A (2002). Characterization of synergy between Cucumber mosaic virus and potyviruses in cucurbit hosts. Phytopathology 92: 51-58. (https://doi. org/10.1094/PHYTO.2002.92.1.51).

WILLAMS RJA (1976). Whitefly-transmitted golden mosaic of lima beans in Nigeria. Plant Disease Reporter 60: 853-857.

ZANARDO LG, CARVALHO CM (2017). Cowpea mild mottle virus (Carlavirus, Betaflexiviridae): a review. Tropical Plant Pathology 42: 417-430. (https://doi.org/10.1007/s40858-017-0168-y).

ZANARDO LG, SILVA FN, LIMA ATM, MILANESI DF, CASTILLO-URQUIZA GP, ALMEIDA AMR, ZERBINI FM, CARVALHO CM (2014). Molecular variability of cowpea mild mottle virus infecting soybean in Brazil. Archives of Virology 159: 727-737. (https://doi.org/10.1007/s00705-013-1879-0).

ZITTER TA, MURPHY F (2009). Cucumber mosaic. The Plant Health Instructor. (https://doi. org/10.1094/PHI-I-2009-0518-01). 